\title{
Optimisation of a Numerical Model to Simulate the Dispersion and Chemical Transformations Within the Oxides of Nitrogen/Ozone System as Traffic Pollution Enters an Urban Greenspace
}

\author{
Dewi Komalasari ${ }^{1} \cdot$ Zongbo Shi $^{1}$ (D) Roy M. Harrison ${ }^{1,2}$ (D)
}

Received: 12 August 2021 / Revised: 4 October 2021 / Accepted: 5 October 2021 / Published online: 28 October 2021

(c) The Author(s) 2021

\begin{abstract}
Urban greenspace has many health benefits, including cleaner air than the surrounding streets. In this study, a detailed exercise has been conducted to measure concentrations of $\mathrm{NO} / \mathrm{NO}_{2} / \mathrm{NO}_{x}$ and $\mathrm{O}_{3}$ within an urban greenspace, the University of Birmingham campus, using continuous analysers, as well as transects of $\mathrm{NO}_{2}$ measured with diffusion tubes. Concentrations have been simulated using the ADMS-Roads model which has been optimised initially using $\mathrm{NO}_{x}$ concentrations for traffic emissions on surrounding roads, background concentrations, and meteorological data considering four candidate sites. Optimisation for prediction of $\mathrm{NO}_{2}$ shows the critical importance of the $\mathrm{NO}_{2}: \mathrm{NO}_{x}$ ratio in traffic emissions, for which a derivation from atmospheric measurements is consistent with a value derived from optimisation of the model fit to roadside data. After optimisation, the model gives an excellent fit to continuous data measured at roadside. Comparison of model predictions with transects of $\mathrm{NO}_{2}$ across the greenspace also show generally good model performance. The incorporation of dry deposition processes for the nitrogen oxides into the model leads to a reduction of less than $1 \%$ in predicted concentrations, leading to the conclusion that the cleaner air within urban greenspace is primarily the result of dispersion rather than deposition processes.
\end{abstract}

Keywords Nitrogen oxides · Ozone $\cdot$ Urban greenspace $\cdot$ Dispersion model $\cdot$ Diffusion tubes $\cdot$ ADMS

\section{Introduction}

Numerous studies have demonstrated the health benefits of urban greenspace (Richardson and Mitchell 2010; Kondo et al. 2018). These are largely associated with the psychological benefits associated with open air and nature, and the physical benefits accruing from activity and exercise. A further benefit derives from the lower air pollutant concentrations in urban parkland. As many urban parks are located close to heavily trafficked roads, a key issue is the dispersion of traffic pollution into parks, and the gradient in concentrations away from the road. In this context, the pollutants

Roy M. Harrison

r.m.harrison@bham.ac.uk

1 School of Geography, Earth and Environmental Sciences, University of Birmingham, Edgbaston, Birmingham B15 2TT, UK

2 Department of Environmental Sciences/Center of Excellence in Environmental Studies, King Abdulaziz University, PO Box 80203, Jeddah 21589, Saudi Arabia of greatest concern are likely to be particulate matter and nitrogen dioxide. In the case of the former, the roadside increment above background tends to be quite small due to the large regional background, while for $\mathrm{NO}_{2}$, the regional background is less substantial and a large increment exists at roadside (Harrison et al. 2021). The decay of this roadside increment as air advects into the park is a key issue in determining human exposure, and in urban design to minimise use of more polluted locations for exercise. Research on $\mathrm{PAH}$, for example, has shown that sporting walkways adjacent to roads are subject to traffic pollution (Alghamdi et al. 2021).

Road traffic is a major source of $\mathrm{NO}_{x}$, which comprises both nitric oxide (NO) and nitrogen dioxide $\left(\mathrm{NO}_{2}\right)$. Only the latter is considered toxic and a risk to public health. Emissions from traffic comprise mostly NO, but over recent years there has been a substantial increase in the proportion of $\mathrm{NO}_{2}$ to around $25 \%$ of $\mathrm{NO}_{x}$, fleet averaged, which more recently has been declining (Carslaw et al. 2019). $\mathrm{NO}_{2}$ is also formed from the oxidation of NO by ozone $\left(\mathrm{O}_{3}\right)$, 
typically leading to an increasing $\mathrm{NO}_{2}: \mathrm{NO}_{\mathrm{x}}$ ratio with distance from the road.

Numerical modelling of traffic-generated $\mathrm{NO}_{2}$ concentrations requires optimisation of a number of separate factors. These include the $\mathrm{NO}_{x}$ source term which depends upon the traffic flow, the mix of vehicle types, and the mean speed of the vehicles. If hourly data are to be calculated, a diurnal variation of the emissions has to be input. It is necessary to specify the proportion of $\mathrm{NO}_{2}$ in the exhaust gases (fleet average), and the model utilised in this work (ADMS-Roads) estimates the subsequent conversion of NO to $\mathrm{NO}_{2}$ and hence the atmospheric $\mathrm{NO}_{2}: \mathrm{NO}_{\mathrm{x}}$ ratios. ADMS also models the dispersion of $\mathrm{NO}_{x}$ using an advanced Gaussian formulation which requires the input of meteorological data, explicitly the wind speed and direction, temperature and relative humidity, and cloud cover, used to estimate atmospheric stability. There may be a need to optimise the wind data. The influence of dry deposition on concentrations was also evaluated using the model. Most studies of roadside dispersion of pollutants use Gaussian plume formulations, although data-driven (Artificial Intelligence) approaches are now available for use in situations, unlike this study, in which a large pre-existing air quality training dataset is available (Li et al. 2020; Vairo et al. 2020; Samal et al. 2020). There are also other situations, such as transfer of hydrocarbons from refineries which require high quality model simulations to estimate ground-level exposures (Milazzo et al. 2017; Ancione et al. 2021).

In this study, hourly measurements were made of NO, $\mathrm{NO}_{2}$ and $\mathrm{O}_{3}$ at a roadside location by a major highway, and downwind in the centre of an area of greenspace. These were supplemented by diffusion tube measurements of 14to 21-day average nitrogen dioxide at multiple locations at different distances from the highway. The sensitivity to the various input variables was evaluated and the model optimised to simulate the distribution of $\mathrm{NO}_{2}$ concentrations in the predominantly downwind direction. This paper provides a case study of model construction and optimisation.

\section{Experimental}

\subsection{Site Location and Sampling Sites}

The site location is shown in Fig. 1. This domain is in a suburban area to the south of the centre of the city of Birmingham, UK, a city of 1.1 million population in a contiguous conurbation of 2.5 million.

All air sampling was conducted within the University of Birmingham campus. The BROS (roadside), EROS and Biosciences (background) sites were equipped with continuous analysers for oxides of nitrogen and ozone. $\mathrm{NO}, \mathrm{NO}_{2}$, and $\mathrm{NO}_{x}$ were measured using chemiluminescence analysers, type 42i from Thermo Scientific, and 42C type from Thermo Environmental Instruments. These were calibrated each week with NO calibration gas at multiple concentrations and intercompared one with the other periodically. Calibration and sensitivity adjustments were made according to BS EN 14211:2012. $\mathrm{O}_{3}$ was measured using UV absorption analysers, type 49i from Thermo Scientific. These are based upon a photometric principle and should not need calibration but were checked periodically for drift using ozone generated from a Pen-ray lamp, and adjusted according to protocol EN 14625:2012. The analyser inlets were at a height of $3.2 \mathrm{~m}$ above ground-level, and for the BROS site at a horizontal distance of $3.6 \mathrm{~m}$ from the nearest vehicles. The continuous data were collected from 2 to 11 February 2018. Subsequently, continuous data were collected at the University Biosciences building.

$\mathrm{NO}_{2}$ was also measured in this study using diffusion tubes of the Palmes type. This type of diffusion tube consists of a plastic tube, two stainless steel grids (\#100 mesh) with absorbent reagent and two end caps, one of which is removed during air sampling. $\mathrm{NO}_{2}$ in the ambient air is captured by the triethanolamine (TEA) absorbent ( $20 \%$ in water) which coats the grid at the inner end of the tube. After exposure, nitrite $\left(\mathrm{NO}_{2}^{-}\right)$which is collected on the grids is extracted and reacted with reagents (sulfanilamide and $N$-(1-naphthyl)-ethylenediamine dihydrochloride (NEDD)) to form a purple solution. The intensity of the colour of the purple solution is measured by a spectrophotometer and the concentration of nitrite in the sample is obtained using calibration from standard nitrite solutions. Then, the average ambient concentration of $\mathrm{NO}_{2}$ can be calculated (Bryan and Grisham 2007; Patton and Kryskalla 2011; Targa and Loader 2008).

Preparation and analysis of diffusion tubes were conducted in a laboratory at the University of Birmingham (UK). The method used for the preparation of the sample solutions and the standard nitrite solutions for the UV-Vis analysis is taken from Targa and Loader (2008). $\mathrm{NO}_{2}{ }^{-}$measurements were performed by UV-Vis analysis, using a Spectrometer Jenway 6800, scanning the wavelength from 530 to $550 \mathrm{~nm}$, and taking the optimum absorbance at $540 \mathrm{~nm}$. Temperature-dependent diffusion coefficients were calculated according to Targa and Loader (2008) and used to convert nitrite concentrations to $\mathrm{NO}_{2}$ in air, using also the dimensions of the tube. Diffusion tubes were deployed in triplicate at each site and the mean concentration used, after elimination of outlier data according to relative standard deviation (RSD) as recommended by Targa and Loader (2008) using a criterion of $15 \%$ to identify outliers. Additionally, since diffusion tubes are well known to be subject to bias, a bias correction was calculated using tubes exposed alongside the continuous analysers by regression of the diffusion tube data upon the automatic analyser data. The tubes 


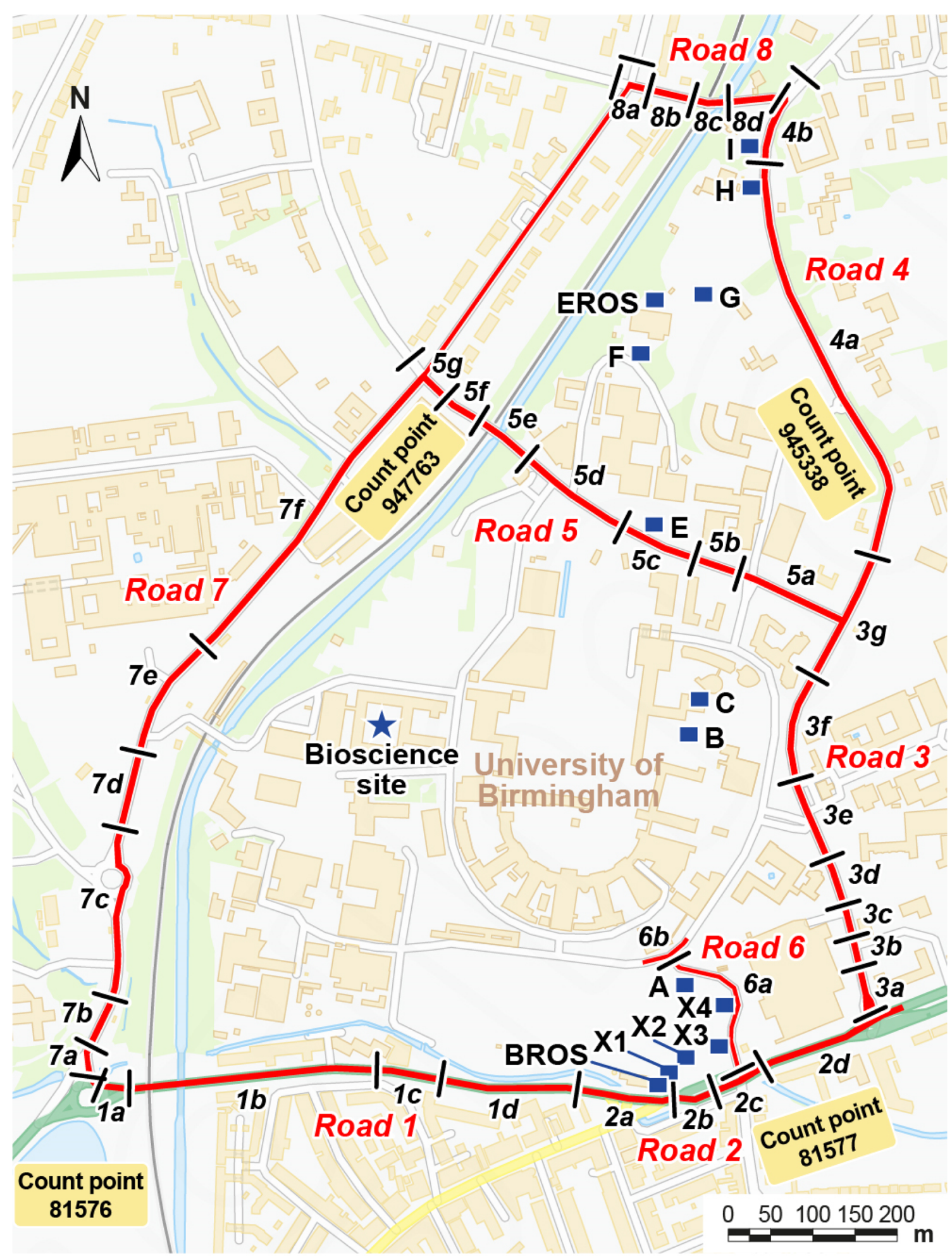

(c) Crown copyright and database rights 2021 Ordnance Survey (100025252).

Fig. 1 The study domain. The red lines indicate roads, with the largest source being the heavily trafficked A38 road which runs almost east-west near the bottom of the map. Sampling sites are indicated by blue squares. The automatic analyser stations at BROS, EROS and Biosciences are labelled, and the other sampling sites which had diffusion tubes for $\mathrm{NO}_{2}$ 
were deployed at a height of $2.6-3.2 \mathrm{~m}$. The modelling was carried out on diffusion tube deployments from 18 March to 15 April 2018, 15 April-13 May 2018, 21 October-20 November 2018, 20-28 November 2018 and 28 November-6 January 2019.

\subsection{Model Construction and Optimisation}

A modelling study of the dispersion process was carried out using ADMS-Roads (version 4.1) to simulate the processes of dispersion and deposition of pollutants. The model is a new generation Gaussian plume model, meaning that atmospheric stability is categorised by use of two parameters, the boundary layer depth and Monin-Obukhov length rather than the Pasquill-Gifford stability categories. Dispersion under convective meteorological conditions uses a skewed Gaussian distribution. The full details of the mathematical formulation are available from the model developers (CERC 2021a). The model has been extensively validated against real world datasets (CERC 2021b), although others have argued that the Gaussian formulation can be improved by reformulation (Chen and Broday 2020). It was selected as it is widely used internationally and performs well when compared with other models with similar capabilities (CERC 2021b). The model includes a chemistry module which accounts for conversions within the $\mathrm{NO} / \mathrm{NO}_{2} / \mathrm{O}_{3}$ system. This is a complex reaction system with many interactions (Sillman 1999). The rapid photochemistry in the roadside environment can be described more simply, and ADMSRoads uses the Generic Reaction Set of eight reactions proposed by Venkatram et al. (1994) to simulate the transformations within the system. The meteorological data used as input in the model were obtained from the nearest weather stations. Following the recommendation of the model developers to assume level terrain if slopes were less than 1 in 10, no terrain corrections were applied. The model validation was performed initially using the observation data collected from the $\mathrm{NO}_{x}$ and $\mathrm{O}_{3}$ automatic analysers during the period from 2 to 11 February 2018 at BROS and EROS. The $\mathrm{NO}_{2}$ concentrations from diffusion tubes measured at 14 points in the University of Birmingham site were then compared with the modelling results.

\subsubsection{Source Strength}

In ADMS-Roads, the pollutant sources are divided into road sources and industrial sources. For the road sources, the road elevation, width, and canyon height are inputted. The pollutant emissions can be set manually or can be estimated by the software based on the input for the traffic flows, which includes average speed in $\mathrm{km} /$ hour and the vehicle count/ hour in each vehicle category. The emission factor $\left(\mathrm{g} \mathrm{km}^{-1}\right)$ and emission rate $\left(\mathrm{g} \mathrm{km}^{-1} \mathrm{~s}^{-1}\right)$ are automatically calculated by the model based on the input data. The EFT (Emission Factors Toolkit) was used to calculate the emission rates at the location for a specific year, vehicle speed, road type (e.g., urban, rural or motorway) in each vehicle category (e.g., light duty, LDV, and heavy-duty vehicles, HDV).

In the model, roads are designated as line sources. Line sources near the receptors are included explicitly in the model, and roads far from the receptors are considered only through their contribution to the background (Heist et al. 2013). Emissions rates are derived using data on vehicle speed, vehicle type, number of vehicles, etc. Traffic flow data were generated from the Department for Transport (https://roadtraffic.dft.gov.uk/local-authorities/141) based upon vehicle count (Average Annual Daily Flow-AADF) for the roads with data available. Each road was divided into segments in terms of road width $(\mathrm{m})$ and speed in kilometres per hour $\left(\mathrm{km} \mathrm{h}^{-1}\right)$, shown in Fig. 1. A list of road links appears in Table S1. The diurnal variation of traffic flows was taken from TRA0307 (Figure S1), vehicle traffic distribution data from the Department for Transport, UK. These differ for weekdays, Saturdays and Sundays and are shown in Table $\mathrm{S} 2$.

There are eight roads identified, as shown in Fig. 1 and Table S1, and only two locations have the Dept. of Transport AADF data, ID numbers 81576 and 81577 . For roads with no AADF data, the result from manual one-hour observation data on vehicles count was used, after extrapolation to $24 \mathrm{~h}$ based upon the diurnal profiles in TRA0307. The average hourly vehicle flows for the different roads appear in Figure S2. The speed of vehicles near traffic lights was set in the model at the lowest speed, $5 \mathrm{~km} \mathrm{~h}^{-1}$, and sensitivity analysis of this value was conducted. In other locations, vehicle speeds were measured by manually timing vehicles over fixed distances. A default value of primary $\mathrm{NO}_{2}: \mathrm{NO}_{x}$ in the fleet average exhaust emissions of $23.8 \%$ (molar) was adopted initially and varied subsequently in a sensitivity test.

\subsubsection{Meteorology}

The meteorological data should ideally be generated from the nearest weather station, and data for wind direction, wind speed, temperature, and relative humidity (RH) were taken from the nearest weather station, which is Winterbourne No. 2 (1.0 km from BROS) when available, or when unavailable, other sites at Coundon $(27.0 \mathrm{~km})$, Coleshill $(16.5 \mathrm{~km})$ or Elmdon $(12.7 \mathrm{~km})$ had data available. Cloud cover data were only available from the Coleshill weather station.

For the surface roughness, a value of $0.5 \mathrm{~m}$ was selected which corresponds to parkland and suburban areas. A sensitivity study was conducted in which roughness lengths of $1.0 \mathrm{~m}$ (recommended for cities and woodland) and $1.5 \mathrm{~m}$ (large urban areas) were also modelled. 


\subsubsection{Background Concentrations}

Background concentrations of pollutants were obtained from the nearest air quality monitoring station, which was the EROS site (when available), Biosciences site, or Birmingham, Acocks Green, a national network (AURN) urban background site. Data from the EROS site were preferred as this site is within the model domain and shown by modelling not to be greatly affected by emissions from the local highways. The Acocks Green site is $7 \mathrm{~km}$ from EROS, and a comparison of data showed that it typically measured higher concentrations than EROS, especially for wind sectors with a northerly component.

\subsection{Statistical Evaluation of the Model}

Pollutant concentrations from on-site measurements were compared to concentrations from the modelling results during the specific sampling time. Fractional bias (FB), normalised mean square error (NMSE) and correlation coefficient (R) are statistics used to evaluate model performance (Briant et al. 2013; Chang and Hanna 2004; Dẻdelè and Miškinyte 2015; Heist et al. 2013; Hirtl and BaumannStanzer 2007; Hood et al. 2018; Owen et al. 1999):

Fractional bias, $F B=\frac{\left(\bar{C}_{\mathrm{o}}-\bar{C}_{\mathrm{m}}\right)}{0.5\left(\bar{C}_{\mathrm{o}}+\bar{C}_{\mathrm{m}}\right)}$,

Normalised mean square error, NMSE $=\frac{\left(\overline{C_{\mathrm{o}}-C_{\mathrm{m}}}\right)^{2}}{\bar{C}_{\mathrm{o}} \bar{C}_{\mathrm{m}}}$,

Correlation, $R=\frac{1}{n-1} \sum_{i=1}^{n}\left(\frac{C_{\mathrm{o}}-\bar{C}_{\mathrm{o}}}{\sigma C_{\mathrm{o}}}\right)\left(\frac{C_{\mathrm{m}}-\bar{C}_{\mathrm{m}}}{\sigma C_{\mathrm{m}}}\right)$,

where, $C_{\mathrm{o}}$ is the observed value of pollutant concentration; $C_{\mathrm{m}}$ is the modelled value of pollutant concentration; overbar $C_{\mathrm{o}}$ is the average of observed values of pollutant concentration; overbar $C_{\mathrm{m}}$ is the average of modelled values of pollutant concentration; $\sigma C_{\mathrm{o}}$ is the standard deviation of observed concentrations and $\sigma C_{\mathrm{m}}$ is the standard deviation of modelled concentrations.

\subsubsection{Fractional Bias (FB)}

FB is mean systematic bias, reviewing the mean difference between the observed and modelled values, and the ideal value of FB is zero (Chang and Hanna 2004; Heist et al. 2013; Hood et al. 2018). A negative FB means the model over-estimates the measured data, and positive FB means the measured data is under-estimated (Hirtl and BaumannStanzer 2007).

\subsubsection{Normalised Mean Square Error (NMSE)}

NMSE measures the overall deviations, reviewing the systematic and random errors. The ideal value of NMSE is zero (Chang and Hanna 2004; Heist et al. 2013; Hood et al. 2018).

\subsubsection{Coefficient of Correlation (R)}

Coefficient of correlation demonstrates the strength of correlation and linear relationship between the observed and predicted data (Chang and Hanna 2004; Heist et al. 2013; Hood et al. 2018). The range of $\mathrm{R}$ is between -1 and 1 . The value near -1 or 1 indicates there is a strong relationship between the modelled and the observed data.

\subsubsection{Coefficient of Determination $\left(R^{2}\right)$}

Coefficient of determination represents the total variation of data that one variable can predict in the other variable's data, in range value $0-1$.

\section{Results and Discussion}

The flow chart for the model design and optimisation is shown in Fig. 2. The model was set up initially to estimate hourly average concentrations which could be compared with the concentrations measured with the continuous analysers at the BROS and EROS sites. There was a sequence of optimisation through sensitivity studies.

\subsection{Meteorological Data}

The first task was to select meteorological data, and data were available from four sites within the local region. An intercomparison of data showed a good agreement between all weather stations for wind direction, temperature and $\mathrm{RH}$, but not for wind speed. When available, this was taken from Winterbourne No. 2, which is the closest weather station to the sampling area, at a distance of only $1.0 \mathrm{~km}$ from the BROS sampling location. A sensitivity study showed a good fit between modelled and measured $\mathrm{NO}_{x}$ as evidenced by FB and NMSE when using wind data from this site. Wind data for other sites gave low estimates of concentration, with Coundon the closest fit. For periods when data were unavailable for Winterbourne No. 2, data from the Coundon station were adopted after correction to Winterbourne No. 2 equivalent values 


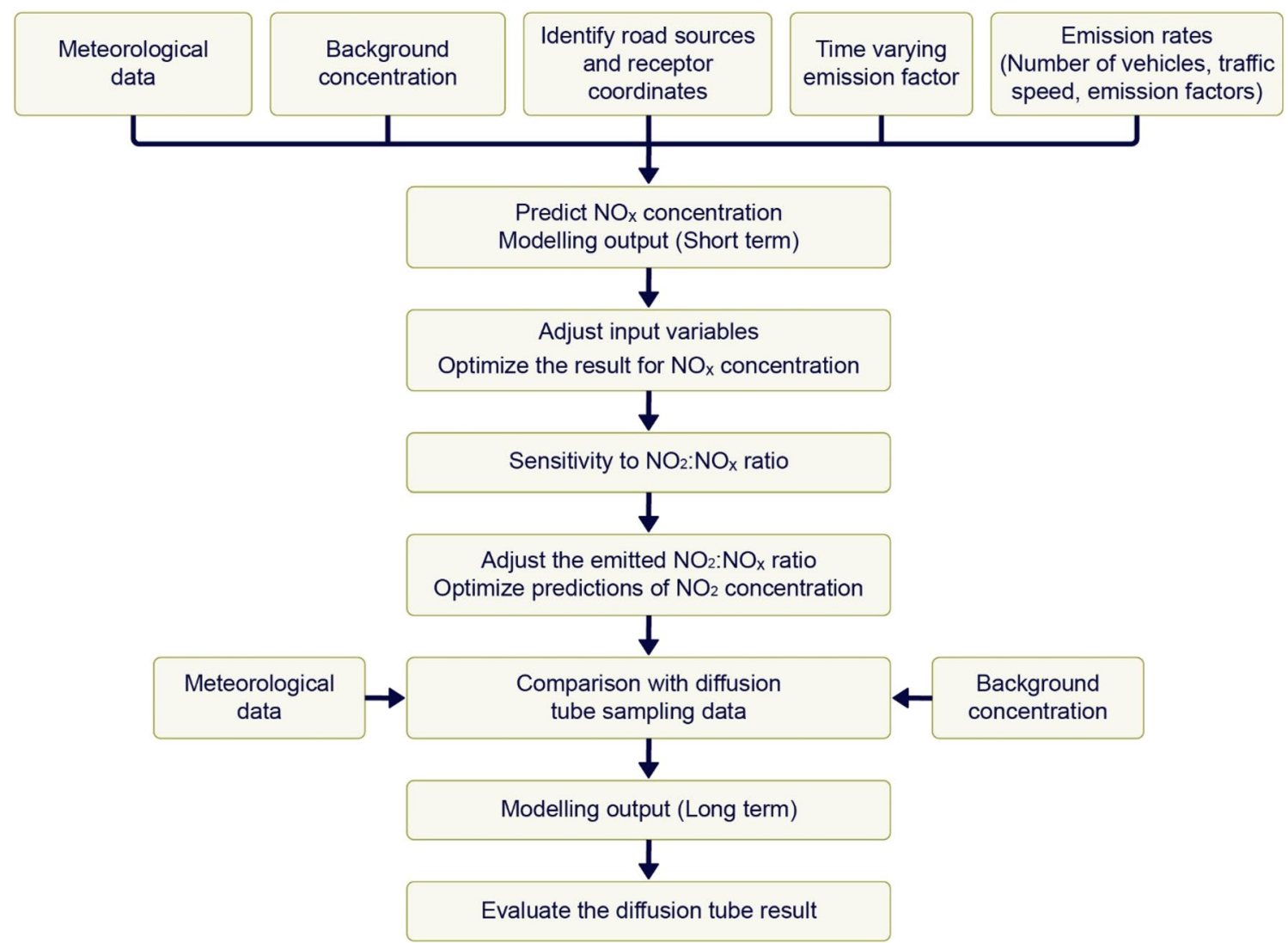

Fig. 2 Flow chart of model construction and optimisation

using a regression equation derived from 30 months (January 2016-June 2018) of simultaneous data from the two sites:

$y=1.5101 x+0.5464 \mathrm{~m} \mathrm{~s}^{-1}$

in which $y$ is Coundon and $x$ is Winterbourne wind speed.

The sensitivity study was run with roughness lengths of $1.0 \mathrm{~m}$ and $1.5 \mathrm{~m}$ applied to both the meteorological station and field site data to compare with the baseline simulation of $0.5 \mathrm{~m}$, and applied to the periods of 15 April-13 May 2018 and 20-28 November 2018. In both cases of larger roughness lengths, the model predicted higher concentrations of $\mathrm{NO}_{x}$ within $10 \mathrm{~m}$ of the road, and reduced concentrations subsequently. The near road increase in $\mathrm{NO}_{x}$ concentration was up to $3.5 \%$ at $3.6 \mathrm{~m}$ for a $1.0 \mathrm{~m}$ roughness length and a decrease of generally $<1 \%$ beyond $10 \mathrm{~m}$. The corresponding figures for a roughness length of $1.5 \mathrm{~m}$ were $+6.5 \%$ at $3.6 \mathrm{~m}$ and generally $<-2 \%$ at $>10 \mathrm{~m}$ downwind distance. We therefore conclude that the model is not strongly sensitive to the choice of roughness length.

\subsection{Background Concentration}

The next sensitivity test was to the background concentration which forms a major part of the measured concentration at the BROS site. As pollutant concentrations decline quite sharply with distance from a road, it was decided to test the use of EROS as a background as this is in the centre of the greenspace and well separated from any road. The model was run using EROS data as background, and the concentrations predicted for EROS showed low FB and NMSE indicating a good model fit and confirming that the road network surrounding the greenspace had a low impact at this location. It was, therefore, decided to use EROS concentrations as the background for modelling periods when such data were available. For most of the periods with diffusion tube measurements, this was not the case and data from another site had to be selected. In most cases, this was the Biosciences site within the University campus, but not directly on the transect from BROS to EROS (see Fig. 1). 
Data were also available from one national network (AURN) urban background site within Birmingham, Acocks Green. This showed generally higher concentrations than those measured at the EROS and Biosciences sites.

\subsection{Vehicle Emissions}

The next input to be optimised was the vehicle speeds. These are derived from measured data, except in the vicinity of road junctions, where average speeds are hard to measure. For these locations, model runs were conducted with minimum average vehicle speeds of 5,8 and $10 \mathrm{~km} \mathrm{~h}^{-1}$, and judging from the low FB and NMSE in the prediction of $\mathrm{NO}_{x}$ concentrations at BROS seen in Table 1, the best fit was for a minimum vehicle speed of $10 \mathrm{~km} \mathrm{~h}^{-1}$ which was adopted for further runs. The model was then run to predict $\mathrm{NO}_{2}$ concentrations at BROS and showed a substantial overestimation, by about $20 \%$. This led to a sensitivity study in which the $\mathrm{NO}_{2}: \mathrm{NO}_{x}$ ratio was varied, taking values of 10,15 and $20 \%$, all below the default value of $23.8 \%$ in the model. A ratio of $15 \%$ gave the lowest values of FB and NMSE (Table 2) and a regression of modelled ( $y$ ) versus measured (x) $\mathrm{NO}_{2}$ concentrations gave:

$y=0.9957 x+0.723 \mu \mathrm{g} \mathrm{m}^{-3} \quad R^{2}=0.7745$.

A comparison of modelled with measured data appears in Fig. 3 and shows that the model now captures the main features of the variations in nitrogen dioxide.

The best fit for $\mathrm{NO}_{2}: \mathrm{NO}_{x}$ ratio can be tested with real data. $\mathrm{NO}_{2}: \mathrm{NO}_{x}$ ratio can be estimated by calculating the relative concentration of oxidant per unit $\mathrm{NO}_{x},\left(\mathrm{NO}_{2}+\mathrm{O}_{3}\right) /$ $\mathrm{NO}_{x}$, at near road and background sites (Carslaw et al. 2016;
Jenkin 2004). This is based upon the concept that although there may be oxidation of $\mathrm{NO}$, and hence an increase in $\mathrm{NO}_{2}$, this is exactly compensated in molar terms by a decrease in $\mathrm{O}_{3}$, and hence levels of $\mathrm{O}_{x}$ are conserved in the background air, and any increment in $\mathrm{O}_{x}$ between the roadside and downwind site is due to the primary emission of $\mathrm{NO}_{2}$ (Table 3 ).

$\Delta \mathrm{O}_{x}$ is due to the primary emission of $\mathrm{NO}_{2}$, as the timescales are too short for significant formation of ozone from photochemistry. Concentration changes $(\Delta)$ between EROS (taken as representative of the background) and BROS were:

$\Delta \mathrm{O}_{x}=3 \mathrm{ppb}$

$\Delta \mathrm{NO}_{x}=22 \mathrm{ppb}$

Primary $\mathrm{NO}_{2}=\frac{\Delta \mathrm{O}_{x}}{\Delta \mathrm{NO}_{x}} \times 100 \%$

Primary $\mathrm{NO}_{2}=(3 / 22) \times 100 \%=13.6 \%=\sim 14 \%$.

The result suggests that the primary $\mathrm{NO}_{2}$ level is approximately $14 \%$, and highly consistent with that estimated from optimisation of the model.

Table 3 shows that concentrations of ozone changed little between the BROS and EROS sites, with just a small decline due to reaction with $\mathrm{NO}$, and hence model results are not shown for this pollutant, although it was a key input to the modelling.

\subsection{Dry Deposition}

Thus far, the model had run without inclusion of dry deposition, a reasonable approximation due to the relatively short distances of travel. Deposition processes were however

Table 1 Model evaluation of different vehicle minimum speeds

\begin{tabular}{llllllllrr}
\hline $\begin{array}{l}\text { Setting minimum } \\
\text { ehicle speed } \\
\left(\mathrm{km} \mathrm{h}^{-1}\right)\end{array}$ & Pollutant & $\begin{array}{l}\text { Measured } \\
\text { mean }\left(\mu \mathrm{g} \mathrm{m}^{-3}\right)\end{array}$ & $\begin{array}{l}\text { Modelled } \\
\text { mean } \\
\left(\mu \mathrm{g} \mathrm{m}^{-3}\right)\end{array}$ & SD measured & SD modelled & $\begin{array}{l}\text { FB (frac- } \\
\text { tional bias) }\end{array}$ & NMSE & $R$ & $R^{2}$ \\
\hline 5 & $\mathrm{NO}_{x} \mathrm{BROS}$ & 69.01 & 76.88 & 46.62 & 58.28 & -0.11 & 0.012 & 0.78 & 0.61 \\
8 & $\mathrm{NO}_{x} \mathrm{BROS}$ & 69.01 & 67.81 & 46.62 & 49.82 & 0.02 & 0.000 & 0.80 & 0.64 \\
10 & $\mathrm{NO}_{x} \mathrm{BROS}$ & 69.01 & 65.32 & 46.62 & 47.41 & 0.05 & 0.003 & 0.80 & 0.64 \\
\hline
\end{tabular}

Table 2 Model evaluation of different setting $\mathrm{NO}_{2}: \mathrm{NO}_{x}$ ratio

\begin{tabular}{|c|c|c|c|c|c|c|c|c|c|}
\hline $\begin{array}{l}\text { Setting } \\
\mathrm{NO}_{2}: \mathrm{NO}_{x} \text { ratio } \\
(\%)\end{array}$ & Pollutant & $\begin{array}{l}\text { Measured } \\
\text { mean }\left(\mu \mathrm{g} \mathrm{m}^{-3}\right)\end{array}$ & $\begin{array}{l}\text { Modelled mean } \\
\left(\mu \mathrm{g} \mathrm{m}^{-3}\right)\end{array}$ & SD measured & SD modelled & $\begin{array}{l}\text { FB (frac- } \\
\text { tional bias) }\end{array}$ & NMSE & $R$ & $R^{2}$ \\
\hline 10 & $\mathrm{NO}_{2}$ BROS & 28.95 & 27.74 & 15.61 & 14.16 & 0.04 & 0.002 & 0.89 & 0.79 \\
\hline 15 & $\mathrm{NO}_{2}$ BROS & 28.95 & 29.55 & 15.61 & 15.55 & -0.02 & 0.000 & 0.88 & 0.77 \\
\hline 20 & $\mathrm{NO}_{2}$ BROS & 28.95 & 31.37 & 15.61 & 16.97 & -0.08 & 0.006 & 0.87 & 0.76 \\
\hline
\end{tabular}


$\mathrm{NO}_{2}: \mathrm{NO}_{\mathrm{x}} \quad$ Graph of $\mathrm{NO}_{2}$ observation and $\mathrm{NO}_{2}$ modelled at BROS

ratio
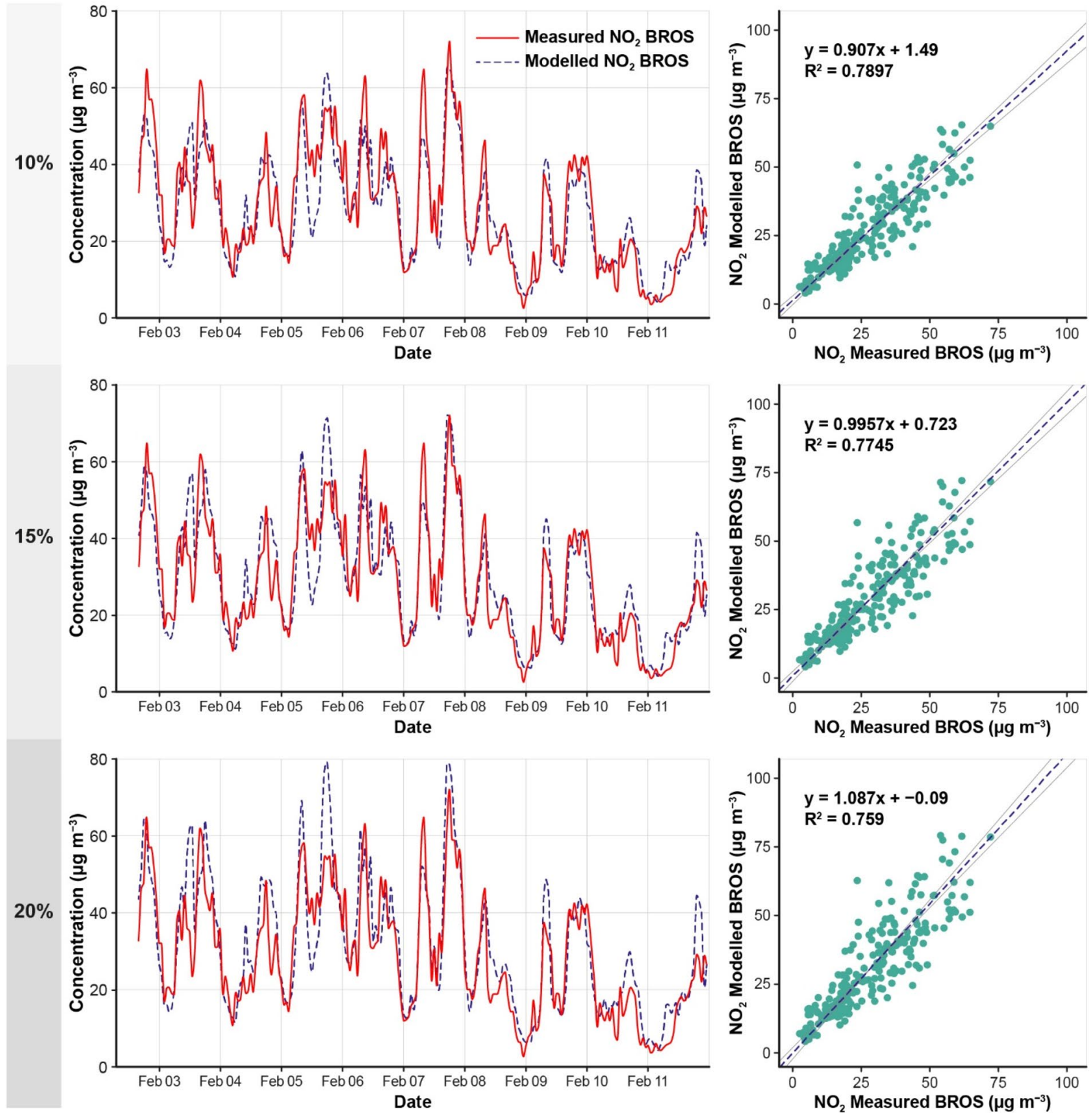

Fig. 3 Measured and modelled concentrations of $\mathrm{NO}_{2}$ using different proportions of primary $\mathrm{NO}_{2}$ in the model

included as a sensitivity investigation using the values of deposition velocity for $\mathrm{NO}$ and $\mathrm{NO}_{2}$ available as a default in ADMS-Roads. Deposition of $\mathrm{O}_{3}$ was not accounted for as the ADMS model does not allow inclusion of deposition for secondary components. Deposition velocities in the ADMS-Roads model were set at $0.0015 \mathrm{~m} \mathrm{~s}^{-1}$ for $\mathrm{NO}_{2}$, and $0.00015 \mathrm{~m} \mathrm{~s}^{-1}$ for $\mathrm{NO}$ as recommended by CERC in normal runs. As a test of sensitivity to dry deposition, the deposition velocity of $\mathrm{NO}_{2}$ was varied between 0.00067 and $0.005 \mathrm{~m} \mathrm{~s}^{-1}$ based upon a survey of literature.
Using as input data the period of automatic analyser measurements from 2 to 11 February 2018, the largest reduction in $\mathrm{NO}_{2}$ concentration was $1.45 \%$ when dry deposition was implemented at the maximum.

\subsection{Modelling the Long-Term Data}

Diffusion tube samplers were deployed over periods of one or more weeks, and hence were not suitable for direct comparison with hourly data from the model. The hourly resolution in the 
Table 3 Mean pollutant concentrations at BROS and EROS sites

\begin{tabular}{llcc}
\hline Pollutant & \multicolumn{2}{l}{$\begin{array}{l}\text { Mean concentra- } \\
\text { tion } \pm \text { uncertainty }(\mathrm{ppb})\end{array}$} & \multicolumn{2}{c}{$\begin{array}{l}\Delta(\mathrm{ppb}) \\
{[\mathrm{BROS}]-[\text { EROS] }}\end{array}$} \\
\cline { 2 - 3 } & BROS & EROS & \\
\hline $\mathrm{NO}$ & $20 \pm 1$ & $2 \pm 0.3$ & $18 \pm 3$ \\
$\mathrm{NO}_{2}$ & $14 \pm 1$ & $10 \pm 0.3$ & $4 \pm 0.3$ \\
$\mathrm{NO}_{x}$ & $34 \pm 2$ & $12 \pm 1$ & $22 \pm 2$ \\
$\mathrm{O}_{3}$ & $17 \pm 1$ & $18 \pm 1$ & $-1 \pm 0.1$ \\
$\mathrm{O}_{x}\left(\mathrm{NO}_{2}+\mathrm{O}_{3}\right)$ & $31 \pm 3$ & $28 \pm 2$ & $3 \pm 0.3$ \\
\hline
\end{tabular}

Uncertainty is expressed by the standard error of the mean, with that for the difference combining the uncertainties in both means

model is needed to account for diurnal changes in emissions and meteorology, and therefore, the hourly model outputs were averaged over the full period of a diffusion tube deployment by selecting the long-term (LT) option on the output tab in the model to obtain the average model outputs for each receptor. When available, background estimates from the EROS site were used, and in other cases, these were taken from the Biosciences site within the campus, or the national network (AURN) station at Acocks Green.

A typical result from the modelling is shown in Fig. 4 which compares the model output with the diffusion tube measurements. It is from the period 15 April-13 May when the winds were predominantly south-westerly, which advects pollution from the road across the campus green space. The model fit to the data is generally good, with a regression of:

$y=0.82 x+5.12 \mu \mathrm{g} \mathrm{m}^{-3} ; \quad R^{2}=0.71$,

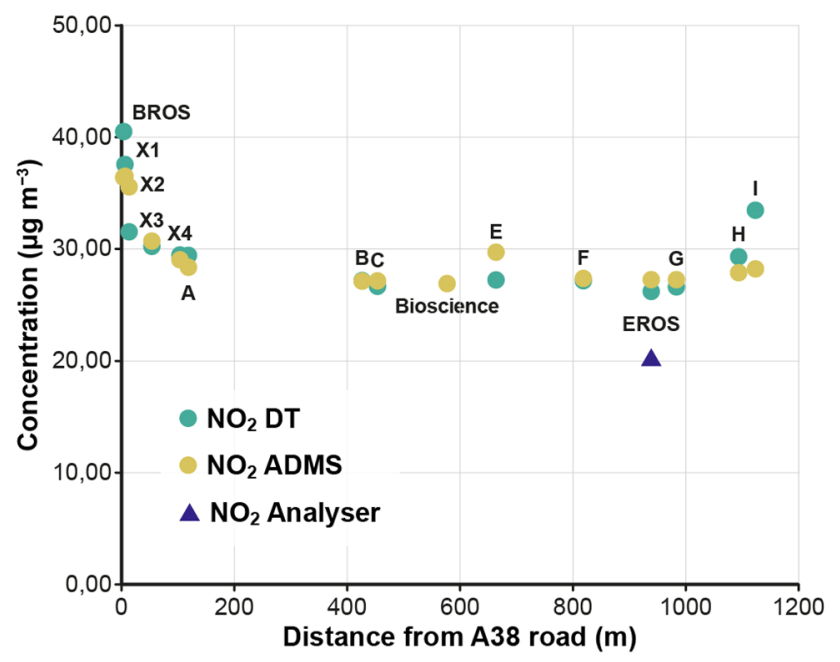

Fig. 4 Transect of modelled and measured $\mathrm{NO}_{2}$ (15 April-13 May 2018)

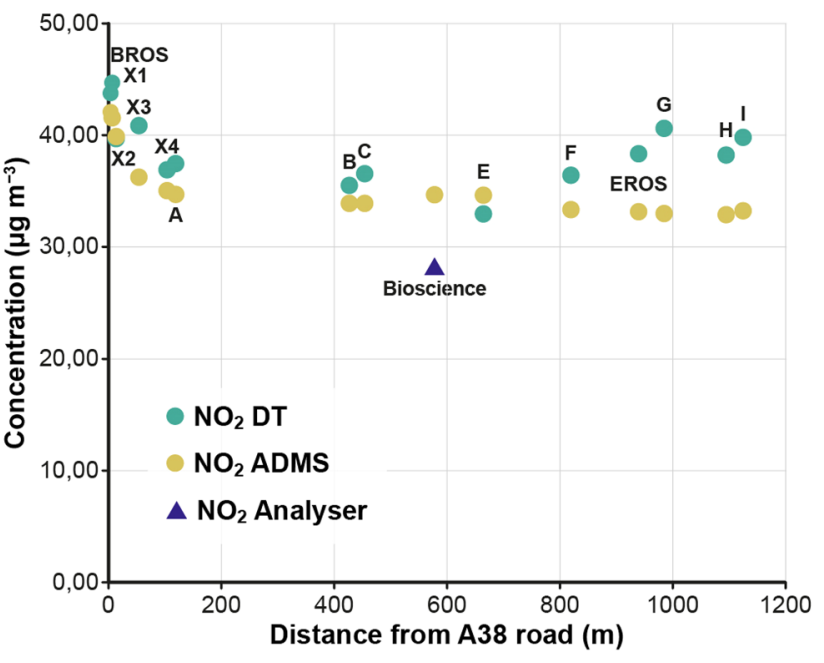

Fig. 5 Transect of measured and modelled $\mathrm{NO}_{2}$ (20-28 November 2018)

where $y$ is the modelled concentration and $x$ is the measurement. The absolute differences between the model and measurements are for most sites $<2 \mu \mathrm{g} \mathrm{m}^{-3}$, and at their greatest $<5 \mu \mathrm{g} \mathrm{m}^{-3}$. Hence the large intercept of $5.1 \mu \mathrm{g} \mathrm{m}{ }^{-3}$ is rather surprising, but results from the large extrapolation from the data to the $y$-axis.

During the period 20-28 November, the winds were predominantly from the north-east, and hence, the pollution from the major A38 highway was mainly carried away from the greenspace. The results shown in Fig. 5 show an elevation in measured concentrations at the sites furthest from the A38 (between EROS and site I) indicating a likely underestimate of emissions from the roads to the north and east of our site, from which only manual traffic measurements were available. In this case, the regression fit also showed an appreciable intercept:

$y=1.01 x-3.57 \mu \mathrm{g} \mathrm{m}^{-3} ; \quad R^{2}=0.47$,

where $y$ is the modelled value and $x$ is the measurement.

\subsection{Concentration Decay}

Both modelled and measured concentrations of $\mathrm{NO}_{2}$ concentrations declined from roadways to background locations within a distance of around $100 \mathrm{~m}$. This result is similar to the findings of other researchers who have that found $\mathrm{NO}_{2}$ concentrations decrease to near background within 150-200 m from a road (Gilbert et al. 2003; Karner et al. 2010; Ducret-Stich et al. 2013). 


\section{Conclusions}

There are few such tests of model set-up and optimisation relating to a complex road layout of this kind, and few relating to pollutant dispersion into greenspace. Several of the input variables are fixed, but many require optimisation. Traffic volumes derive from direct measurements, as do most traffic speed data. However, the main roadside sampling location was close to a road junction, and as mean traffic speeds in such a location were not easy to measure, optimisation of the speed close to road junctions was important. In addition to getting the emissions right, good input meteorological data are crucial. Using data from a nearby station is obviously advantageous, and fortunately this was available for most of the time. A notable feature was that wind speeds at the nearby Winterbourne station were lower by about $35 \%$ than those measured at the best of the other sites with available data. This is presumably due to the drag of urban structures leading to reduced wind speeds within the urban area. When the wind speed data from a site outside the city were used, notably better predictions were obtained if the wind speeds were reduced to equivalent Winterbourne speeds. The choice of background air quality data is crucial, as incorrect data will cause a bias irrespective of the quality of the dispersion model. Optimisation of all of these variables was conducted using measured $\mathrm{NO}_{x}$ concentration data. $\mathrm{NO}_{x}$ is a conserved species over the short timescales and hence is a good test of the quality of the dispersion characterististics of the model.

Another key input is the traffic-emitted $\mathrm{NO}_{2}: \mathrm{NO}_{x}$ ratio. This was optimised independently by tuning the model performance for $\mathrm{NO}_{2}$, once the performance for $\mathrm{NO}_{x}$ was shown to be good. One benefit of the experimental design was that the measured data allowed an independent estimate of this ratio, which emerged to be very close to that derived by optimising the model. This is an important variable, likely to change further as the vehicle fleet evolves with time.

Modelling the full transect across the greenspace proved more challenging for the model than the single site study. However, the model showed good skill, with most absolute model values close to those measured. Extrapolation of the regression to give an intercept could, however, be quite misleading due to the clustering of data points in a relatively small area of the graph. Overall, the results give confidence that with care taken over inputs, the model is highly skillful.

Another key area of investigation was the extent to which dry deposition influences measured concentrations within the greenspace. The model results give a clear indication that the decline in concentrations towards the centre of the greenspace is predominantly the result of dispersion rather than deposition processes. This is consistent with the findings of Jeanjean et al. (2016) and Xing and Brimblecombe (2019) who both concluded that the deposition process influenced concentrations far less than dispersion. However, there are scenarios where dry deposition may be more significant, for example on the scale of an entire city (Tiwari and Kumar 2020), or if the greenspace contained trees which would enhance the deposition process.

Supplementary Information The online version contains supplementary material available at https://doi.org/10.1007/s41748-021-00262-1.

Acknowledgements The authors would like to thank Louisa Kramer, Leigh Crilley and Tara Rasoul for technical assistance with automatic analysers, and Estates Office management at University of Birmingham for the approval of sampling locations.

Funding DK acknowledges the financial support from the Ministry of Research, Technology, and Higher Education of the Republic of Indonesia for a scholarship through Program Research and Innovation in Science and Technology (RISET-Pro), WB No. 8245-ID.

Availability of data and material Data supporting this publication are openly available from the UBIRA eData repository at https://doi.org/ 10.25500/edata.bham.00000704

\section{Declarations}

Conflict of interests The authors do not have any competing financial interests.

Open Access This article is licensed under a Creative Commons Attribution 4.0 International License, which permits use, sharing, adaptation, distribution and reproduction in any medium or format, as long as you give appropriate credit to the original author(s) and the source, provide a link to the Creative Commons licence, and indicate if changes were made. The images or other third party material in this article are included in the article's Creative Commons licence, unless indicated otherwise in a credit line to the material. If material is not included in the article's Creative Commons licence and your intended use is not permitted by statutory regulation or exceeds the permitted use, you will need to obtain permission directly from the copyright holder. To view a copy of this licence, visit http://creativecommons.org/licenses/by/4.0/.

\section{References}

Alghamdi MA, Hassan SK, Al Sharif MY, Khoder MI, Harrison RM (2021) On the nature of polycyclic aromatic hydrocarbons associated with sporting walkways dust: concentrations, sources and relative health risk. Sci Tot Environ 781:146540. https://doi.org/ 10.1016/j.scitotenv.2021.146540

Ancione G, Lisi R, Milazzo MF (2021) Human health risk associated with emissions of volatile organic compounds due to the shiploading of hydrocarbons in refineries. Atmos Pollut Res 12:432442. https://doi.org/10.1016/j.apr.2020.12.004

Briant R, Seigneur C, Gadrat M, Bugajny C (2013) Evaluation of roadway Gaussian plume models with large-scale measurement 
campaigns. Geosci Model Dev 6:445-456. https://doi.org/10. 5194/gmd-6-445-2013

Bryan NS, Grisham MB (2007) Methods to detect nitric oxide and its metabolities in biological samples. Free Radic Biol Med 43:645657. https://doi.org/10.1016/j.freeradbiomed.2007.04.026

Carslaw DC, Murrells TP, Andersson J, Keenan M (2016) Have vehicle emissions of primary $\mathrm{NO}_{2}$ peaked? Faraday Discuss 189:439-454. https://doi.org/10.1039/c5fd00162e

Carslaw DC, Farren NJ, Vaughan AR, Drysdale WS, Young S, Lee JD (2019) The diminishing importance of nitrogen dioxide emissions from road vehicle exhaust. Atmos Environ X. https://doi.org/10. 1016/j.aeaoa.2018.100002

CERC (2021a) Cambridge Environmental Research Consultants, technical specifications. http://www.cerc.co.uk/environmental-softw are/technical-specifications.html. Accessed 24 Sept 2021

CERC (2021b) Cambridge Environmental Research Consultants, model validation. http://www.cerc.co.uk/environmental-softw are/model-validation.html\#: : text=Validation $\% 20$ of $\% 20$ the $\%$ 20ADMS\%20dispersion\%20models\%20has\%20been,complex\% 20 terrain $\% 2 \mathrm{C} \% 20$ chemistry $\% 2 \mathrm{C} \% 20$ deposition $\% 20$ and $\% 20$ plu me\%20visibility.\%20. Accessed 24 Sept 2021

Chang JC, Hanna SR (2004) Air quality model performance evaluation. Meteorol Atmos Phys 87:167-196. https://doi.org/10.1007/ s00703-003-0070-7

Chen S, Broday DM (2020) Re-framing the Gaussian dispersion model as a nonlinear regression scheme for retrospective air quality assessment at a high spatial and temporal resolution. Environ Model and Softw 125:104620. https://doi.org/10.1016/j.envsoft. 2019.104620

Dėdelè A, Miškinytė A (2015) The statistical evaluation and comparison of ADMS-Urban model for the prediction of nitrogen dioxide with air quality monitoring network. Environ Monit Assess 187:1-12. https://doi.org/10.1007/s10661-015-4810-1

Ducret-Stich RE, Tsai MY, Ragettli MS, Ineichen A, Kuenzli N, Phuleria HC (2013) Role of highway traffic on spatial and temporal distributions of air pollutants in a Swiss Alpine valley. Sci Total Environ 456-457:50-60. https://doi.org/10.1016/j.scitotenv.2013. 03.065

Gilbert NL, Woodhouse S, Stieb DM, Brook JR (2003) Ambient nitrogen dioxide and distance from a major highway. Sci Total Environ 312:43-46. https://doi.org/10.1016/S0048-9697(03)00228-6

Harrison RM, Vu TV, Jafar H, Shi Z (2021) More mileage in reducing urban air pollution from road traffic. Environ Intl 149:106329. https://doi.org/10.1016/j.envint.2020.106329

Heist D, Isakov V, Perry S, Snyder M, Venkatram A, Hood C, Stocker J, Carruthers D, Arunachalam S, Owen RC (2013) Estimating near-road pollutant dispersion: a model inter-comparison. Transp Res Part D Transp Environ 25:93-105. https://doi.org/10.1016/j. $\operatorname{trd} .2013 .09 .003$

Hirtl M, Baumann-Stanzer K (2007) Evaluation of two dispersion models (ADMS-Roads and LASAT) applied to street canyons in Stockholm, London and Berlin. Atmos Environ 41:5959-5971. https://doi.org/10.1016/j.atmosenv.2007.03.026

Hood C, MacKenzie I, Stocker J, Johnson K, Carruthers D, Vieno M, Doherty R (2018) Air quality simulations for London using a coupled regional-to-local modelling system. Atmos Chem Phys 18:11221-11245. https://doi.org/10.5194/acp-18-11221-2018

Jeanjean APR, Monks PS, Leigh RJ (2016) Modelling the effectiveness of urban trees and grass on $\mathrm{PM}_{2.5}$ reduction via dispersion and deposition at a city scale. Atmos Environ 147:1-10. https://doi. org/10.1016/j.atmosenv.2016.09.033

Jenkin ME (2004) Analysis of sources and partitioning of oxidant in the UK-Part 2: contributions of nitrogen dioxide emissions and background ozone at a kerbside location in London. Atmos Environ 38:5131-5138. https://doi.org/10.1016/j.atmosenv.2004.05. 055

Karner AA, Eisinger DS, Niemeier DA (2010) Near-roadway air quality: synthesizing the findings from real-world data. Environ Sci Technol 44:5334-5344. https://doi.org/10.1021/es100008x

Kondo MC, Fluehr JM, McKeon T, Branas CC (2018) Urban green space and its impact on human health. Intl J Environ Res Public Health 15:445. https://doi.org/10.3390/ijerph15030445

Li Z, Yim SH-L, Ho K-F (2020) High temporal resolution prediction of street-level $\mathrm{PM}_{2.5}$ and $\mathrm{NO}_{x}$ concentrations using machine learning approach. J Clean Product 268:121975. https://doi.org/10.1016/j. jclepro.2020.121975

Milazzo MF, Ancione G, Lisi R (2017) Emissions of volatile organic compounds during the ship-loading of petroleum products: dispersion modelling and environmental concerns. J Environ Manage 204:637-650. https://doi.org/10.1016/j.jenvman.2017.09.045

Owen B, Edmunds HA, Carruthers DJ, Raper DW (1999) Use of a new generation urban scale dispersion model to estimate the concentration of oxides of nitrogen and sulphur dioxide in a large urban area. Sci Tot Environ 235:277-291. https://doi.org/10.1016/ S0048-9697(99)00205-3

Patton CJ, Kryskalla JR (2011) Colorimetric determination of nitrate plus nitrite in water by enzymatic reduction, automated discrete analyzer methods. US Geol Surv Tech Methods B 5:34. https:// doi.org/10.3133/tm5B8

Richardson EA, Mitchell R (2010) Gender differences in relationships between urban green space and health in the United Kingdom. Social Sci Med 71:568-575. https://doi.org/10.1016/j.socscimed. 2010.04.015

Samal KKR, Babu KS, Panda AK, Das SK (2020) Data driven multivariate air quality forecasting using dynamic fine tuning autoencoder layer, 2020 IEEE 17th India Council International Conference (INDICON), 978-1-7281-6916-3/20/\$31.00 @2020 IEEE. https://doi.org/10.1109/INDICON49873.2020.9342046

Sillman S (1999) The relation between ozone, $\mathrm{NO}_{x}$ and hydrocarbons in urban and polluted rural environments. Atmos Environ $33: 1821-1845$

Targa J, Loader A (2008) Diffusion tubes for ambient $\mathrm{NO}_{2}$ monitoring: practical guidance for laboratories and users. Report to Defra Devolved Administration, AEA Energy \& Environment, Harwell

Tiwari A, Kumar P (2020) Integrated dispersion-deposition modelling for air pollutant reduction via green infrastructure at an urban scale. Sci Tot Environ 723:138078. https://doi.org/10.1016/j.scito tenv. 2020.138078

Vairo T, Rapuzzi A, Lecca M, Fabiano B (2020) A data driven model for ozone concentration prediction in a coastal urban area. Chem Eng Trans 82:379-384. https://doi.org/10.3303/CET2082064

Venkatram A, Karamchandani P, Pai P, Goldstein R (1994) The development and application of a simplified ozone modelling scheme (SOMS). Atmos Environ 28:3665-3678

Xing Y, Brimblecombe P (2019) Role of vegetation in deposition and dispersion of air pollution in urban parks. Atmos Environ 201:7383. https://doi.org/10.1016/j.atmosenv.2018.12.027 